\title{
XXXIX. On some combinations of platina
}

\section{Edmund Davy Esq.}

To cite this article: Edmund Davy Esq. (1812) XXXIX. On some combinations of platina, Philosophical Magazine Series 1, 40:173, 209-220, DOI: 10.1080/14786441208638218

To link to this article: http://dx.doi.org/10.1080/14786441208638218

$$
\text { 曲 Published online: } 27 \text { Jul } 2009 .
$$

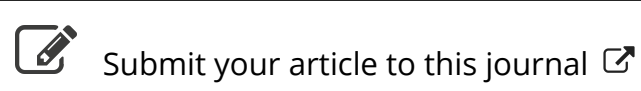

\footnotetext{
Џll Article views: 3
}

Q View related articles $\asymp$ 
Leaving this Platonist *, let us turn to Mr. Leslie's reasoning, and consider how far he is right, and where he deviates from the true line of argument.

This author justly observes, that the same reasoning which proves that there can be no equation between $c$ and $A, B, C$, would equally prove that there can be no equation between $C$ and $a, b, c$. Mr. Leslie might have gone further $;$ for we may without hesitation admit, that the reasoning is just in both cases (provided that we keep to the strict meaning of the word equation), and yel proves nothing in either.

For the argument drawn from the heterogeneity of the quantities no longer applies, when transferred from the angle itself to such functions as the sine, cosine, or arc to a given radius $\uparrow$; these are lines, and of course capable of a comparison with lines; whilst they can not be compared with the angles themselves of which they are called the functions. Hence appears the utter uselessness of Legendre's reasoning. It is true, sir, you have shown that there can be no equation between $c$ and $A, B, C$; but if $\approx, \beta, \gamma$, represent the cosines of $A, B, C$, to any given line $(r)$ as radius, I do not very clearly perceive (from any thing you have delivered) why there might not be such an equation between the five lines $c, \alpha, \beta, \gamma, r$; as would entirely overturn all you mean to establish. There might, for example, be the equation $c=\frac{a^{2} \cdot \beta^{2}}{\gamma r^{2}}$; whence $\gamma=$ $\frac{\alpha^{2} \beta^{2}}{c r^{2}}$; and the angle $C$ would not depend on $A$ and $B$ alone; as you think you have demonstrated.

Sept. 14, 1812 .

X. Y.

P.S.-I must state that I have never seen Mr. Leslie's Geometry, and know nothing more of his argument than is to be gathered from the Edinburgh Review:

XXXIX. On some Combinations of Platina. By EDmund Davy, Esq., of the Royal Institution. Communicated ly the Author.

\section{INTRODUCTION.}

$T_{\text {HE properties which characterize platina, and to which }}$ it owes its value; offer many difficulties to the complete

- Vide Edinburgh Review, October 1809, p. 4.

+ Let it be particularly observed, that I am here speaking geometrically, and do not mean the sine, \&c. to the radius one: this is a number, and supposes a previous choice of some line for unit.

Vol. 40. No.173. Sept. 1819.

0

develop- 
development of its combinations. Hence its chemical history is perhaps less known and more limited than that of any other metal. In the Philusophical Magazine for July, I have described some combinations of platina with sulphur and phosphorus; in the present communication, I shall enter into some details relative to some other compounds of this metal. I shall also venture, on the authority of experiments, to controvert some statements respecting the oxides and salts of platina. I have to regret that other engagements will not allow me leisure to complete the present, together with other investigations I had begun; but I shall rather choose to bring thetn occasionally forward in an imperfect state, than to withhold them entirely, in the anticipation of a period which perhaps may never arrive.

\section{Of the Hydrosulphuret of Platina.}

The compounds obtained by the agency of sulphuretted hydrogen gas on acid solutions of the metals are but imperfectly known, they have not yet been examined with precision; hence, as might be expected, there exists among Chemists a diversity of opinion concerning their constitution. A minute investigation of this class of bodies would serve to elucidate many chemical phænomena relating to the metals, and, there is every reason to believe, would furnish novel and interesting results. It is not my intention to enter into any details relative to the nature of these bodies in general, but simply to confine myself to the consideration of the hydrosulphuret of platina.

This substance may be obtained, by treating a solution of platina with water impregnated with sulphuretted hydrogen gas ; or by passing a current of gas through the solution. After the gas has been passed for a short time through the solution, the surface is covered with a thin coating of a dark iron-gray colour, having the metallic lustre; a quantity of it is also deposited at the bottom of the vessel. As it readily undergoes chemical change in the atmosphere; when it is wanted for accurate experiments, the best mode of procuring it seems to be that I adopted, which will presently be mentioned.

The hydrosalphuret of platina has been partially known for some time ; but it has not I believe been described, nor its composition determined. I do not think it has been at all examined in a state of purity. It has been considered by some chemists as metallic platina; and Dr. Thomson in his System of Chemistry states it as a distinguishing character of platina, that it is precipitated by sulphuretted hy- 
drogen in the metallic'state. M. Proust considered it as a sulphuret, and first noticed a singular property it has of forming sulphuric acid whilst drying in the atmosphere*: This fact has since been observed by Professor Berzelius of Stoskholm, as be lately informed me. In operating on this substance, I soon had occasion to verify the preceding observation of those able chemists; for in cases when it was dried on paper, at the moderate heat of a sand-bath, the paper was burnt by the acid and entirely destroyed. When it was dried at the common temperature of the atmospherey a quantity of acid was also formed. It may not be improper briefly to describe this substance after it has been dried at a gentle heat in the air, and when of course it has undergone parial decumposition.

Its colour is black ; it is in small pieces, the particles of which are loosely coherent. It is destitute of lustre. It marks the fingers or paper, but the lustre is much inferio to that of plumbago. It has a strong acid taste. It is destitute of smell. When heated just below redness on a thin slip of platina, it deflagrates, emitting red sparks, and is partially decomposed; by exposing it to a red heat for some minutes, sulphurenus fumes: are copiously emitted, and the platina remains in a state of purity. It appears to be unaffected by boiling muriatic or sulphuric acid. It is soluble with some little difficulty in boiling nitro-muriatic acid. It is rapidly decomposed, with vivid ignition, when heated with oxymuriate of potash. When it is heated in close vessels over mercury, the products are water, sulphureous acid gas, a minute quantity of sulphur, and a substance analogous in its physical and chemical propertie to the subsulphuret of platina which I have already de scribed. I shall state one experiment which seems to prove this fact. Sorne hydro-sulphuret which had been drying for some days on a sand-bath in a platina crucible, was heated to redness in a retort over merctury : during the process it became partially ignited : the products were similar to those above mentioned: ten grains of the residual: substance were decomposed at a red heat in a platina crus cible; and furnistied 8.5 grains of pure platina. This gives its compsition 85 platina,

$$
15 \text { sulphur, }
$$

100

and if alluwance be made for a minute quantity of sulphus

* Ahnales de Chimië, tome xtix. p. 180.

$\mathrm{O} \mathbf{2}$

expelled 
expelled at the moment of ignition, it almost precisely agrees with the subsulphuret.

As the hydrosulphuret absorbed oxygen, became acid, and attracted water when dried in the atmosphere; it is evident that in such a state it could only furnish variable results, depending entirely on the circumstances to which it had been previously exposed. To obviate these difficulties, it was necessary to have recourse to some mode of obtaining it, by which the agency of the atmosphere would be excluded. As I knew no practicable method of separating the acid from the hydrosulphuret and edulcorating it with distilled water, out of the contact of the air, it became necessary to determine with some degree of precision the agency of air and water on it. With these views, I exposed a surface of recently made hydrosulphuret of platina (which had been well washed with distilled water, and hastily dried with bibulous paper, ) on a platina cover, to a known quantity of oxygen gas; after 20 hours the gas was scarcely diminished, and after about 10 days only $1 \frac{2}{10}$ ths of a cubical inch were absorbed.

Some of the above hydrosulphuret was also put into a bottle filled with distilled water; the water was occasionally examined, but after some days no sensible quantity of sulphuric acid had been formed.

These experiments seemed to prove that this substance might be washed in contact with the atmosphere, without undergoing any perceptible change in its constitution. I shall now state the mode I adopted to procure it. Into a retort of about the capacity of $\mathbf{4 0}$ cubical inches, an aqueous solution of muriate of platina was introduced; it was exhausted of air, and filled with sulphuretted bydrogen gas; a considerable absorption instantly took place, which was much increased by agitation; fresh portions of gas were occasionally admitted, and the process was continued until the fluid became nearly colourless. By this means all the platina may after some time be separated from the solution. The hydrosulphuret precipitated was of a uniform black or very dark brown colour, and exhibited in some places, especially the film on the surface, the metallic lustre. It was now put on a filter, and washed with distilled water till this fluid was tasteless, and did not affect litmus paper; care being taken to keep it during this time always covered with water. Whilst it was yet quite moist and the water still oozing through in drops, it was hastily put into a tubulated retort, to which a stop-cock had been previously 
previously attached; the retort was exhausted twice, and filled with hydrogen or carbonic acid gas. It was exposed to the heat of a sand-hath, and the stop-cock opened under water. After some time the vapour of the water expelled the gas in the retort; when this was effected, the stop-cock was closed, and the neck of the retort kept cold by wet cloths. When the hydrosulphuret had been thus heated in a partial vacuum for about 10 hours, it appeared to be quite dry, and no indications of moisture could be perceived in the bulb of the retort. When cold it was slowly opened over hydrogen gas. In one experiment in which the retort had been previously filled with hydrogen gas, nearly a half of a cubical inch of water was obtained, which had the smell of sulphuretted hydrogen gas, and produced a dark-coloured precipitate with nitrate of lead. I intended to have examined this water more minutely, but was prevented by an accident. It seems probable that it was merely impregnated with a little sulphuretted hydrogen gas, expelled by the agency of heat. In another instance when the hydrosulphuret was procured, the retort being previously filled with carbonic acid gas, the water that came over did not contain any sulphuretted hydrogen gas. I cannot with certainty state the greatest temperature to which the hydrosulphuret had been exposed in these experiments; it was necessarily variable : but from some trials I made with the thermoneter, I have reason to think it could scarcely at any time bave exceeded the boiling point of water. A well sioppered bottle was filled with the dry hydrosulphuret, and it was immediately examined.

\section{Physical and Chemical Properties.}

Its colour was dark brown. It was in small flat lumps, which were readily reduced to powder. Its external surface exhibited a feeble lustre, which was no longer apparen when pulverized. Its lustre was scareely inferior to plumbago when it was rubbed on the fingers or paper. It had no smell. It was insipid when first brought in contact with the tongue; but as it became divided in the mouth, a tolerably strong saline taste was perceived. It scarcely affected litmus paper. When it was put into water, a slight crackling noise was produced; and small bubbles of gas were disengaged. $3 \cdot 2$ grains of hydrosulphuret afforded in this way $T^{15}$ of a cubical inch of gas, which diminished considerably with nitrous gas, and did not burn or explode with a taper. I expected to have found this gas hydrogen, 
and the effect to be connected with the production of sulphuric acid. I was surprised to find that it exhibited the properties of oxygen. I cannot account for this phanomenon; it can scarcely be owing to the absorption of common air, the volume of gas being about eight times greater than that of the bydrosulphuret. When small lumps of it are introduced into nitric acid, a slight detonating noise is produced, and the substance instantly falls to pieces. These effects are connected with the decomposition of the nitric acid and the formation of sulphuric acid, and are much increased, with the rapid disengagement of nitrous gas, on the application of a gentle heat. When a little of the hydrosulphuret is put into concentrated sulphuric acid, gas is disengaged from it : on heating it, a hissing noise is produced, and gas copiously evolved; but it seems to be quite insoluble in this acid. Muriatic, phosphoric, and acetic acids occasion a disengagement of gas from the hydrosulphuret; but the action of these acids on it is very limited, and attended by no other effect worthy of notice. I have not examined the gas evolyed by the agency of these acids on the hydrosulphuret. The quantities on which I have operated have been too small for this purpose. When it is introduced into a strong solution of pure potash or ammonia, a hissing noise is produced; but there is apparently no further effect. When it is exposed to the atmosphere, it absorbs oxygen, and sulphuric acid is formed, Five grains of it exposed in small lumps for four days gained more than $\frac{7}{10}$ ths of a grain in weight, and this increase was in a gradually diminishing ratio, in proportion to the time. It then furnished, by its decomposition in close vessels, sulphureous acid gas, water, and sulphuret of platina. When the hydrosulphuret is heated in nitrous gas, it becomes an ignited mass; when oxygen gas and moisture are present, a white crystallized substance appears to be formed, which furnishes nitrous gas and sulphuric acid by the agency of water. I have not minutely examined these results. Nitrous acid vapour acts spontaneously on the hydrosulphuret, occasions a hissing noise, and the formation of sulphuric acid. When the hydrosulphuret is heated to redness in close vessels over mercury, the products are sulphuretted hydrogen gas, with a little sulphureous acid gas, water, sulphur, and sulphuret of platina. When it is intraduced into chlorine gas, an immediate action is produced, and copious white fumes are evolved; these effects are much increased by the agency of heat, and a substance of a brown and blackish colour is abtained which gives off gas, and is for the most part solu- 
ble in water. It appears to be a muriat of platina with little undecompounded hydrosulphuret.

All these experiments were performed on minute portions of the hydrosulphuret : it would be very desirable to repeat them on larger quantities.

From the foregoing statements, it is evident that the substance obtained by the agency of sulphuretted hydro: gen gas on a solution of platina is not a true sulphuret of this metal. On a comparison of their chemical properties, it will appear that they are decidedly different. Nor can it be, it would seem, a compound of sulphuretted hydrogen gas with oxide of platina, for in this case no stilphuretted hydrogen gas would be furnished by its decomposition in close vessels; water and sulphureous acid gas would be the only results. Now in the actual products water and sulphureous acid gas are found, but in such small quantities, especially the latter, that oxygen and water can only be considered as accidental, and not at all essential to the constitution of the hydrosulphuret. They may fairly be presumed to originate from other sources. The hydrosulphuret was dried at a temperature scarcely exceeding that of boiling water, and there can be no difficulty in admitting that it still contained water. As it absorbed oxygen by exposure to air, and as in the course of the experiments it must necessarily have been exposed for a short time to this agency, the production of a small quantity of sulphureous acid gas is easily accounted for.

The actual results seem to prove that this substance is composed of sulphuret of platina and sulphuretted hydrogen, or of platina, sulphur, and hydrogen; and the facts seem to admit of an easy solution on this idea. The sulphuretted hydrogen may be presumed to be in a loose state of combination' with the sulphuret. Hence, by exposure to the atmosphere, oxygen is absorbed, sulphuric acid and water are formed, and a sulphuret of platina remains which is not affected by the air. The sulphuric acid formed by exposing the hydrosulphuret to the heat of a sand-bath for several days is quite colourless with water; the effect seems to be wholly unconnected with the solution of any of the platina. I have not yet ascertained the precise limits of the decomposition of the bydrosulphuret, by the agency of the air; but it seems highly probable that it will be found to be only in proportion to the quantity of sulphuretted hydrogen it contains. The sulphurets of platina undergo no apparent changes by being exposed to the atmosphere, at least, for several days. 


\section{Analysis.}

The method I employed to ascertain the component part of this substance was of the simplest kind, but I know of no mode which offers more correct results. It is founded on a property, which, in the class of metallic hydrosulphurets, I believe, almost exclusively belongs to those of platina and gold; namely, that of being decompounded by the agency of beat and air, the metal alone remaining in a state of purity. I made many experiments on the hydrosulphuret of platina before I obtained any satisfactory results, Those which nearly agree, and which seem to afford evidences of its constitution, I shall immediately relate.

Experiment 1. Ten grains of hydrusulphuret of platina were heated in a small retort over mercury, gas was soon disengaged, and a little hmpid fluid condensed in the neck of the retort; the heat was continued for several minutes, and when the retort had acquired a dull red, the substance became partially ignited *, a copius evolution of gas immediately ensued, and a little yellow sublimate was deposited. When the gas ceased to come over, and no further change could be produced by the utmost heat of a spiritlamp, the retort was suffered to cool, and the results were carefully examined. The gas obtained, allowance being made for the common air, and corrections for temperature and pressure, amounted to 1.25 of a cubical inch, and was almost entirely sulphuretted hydrogen gas, with a minute, quantity of sulphureous acid gas. On agiation it was absorbed by water, and instantly produced a dark-coloured precipitate with a solution of the nitrates of lead and silver. It had the precise odour of sulphuretted hydrogen gas, and inflamed with a lighted taper in contact with the atmosphere, depositing sulphur on the sides of the tube. The limpid fluid was water impregnated with suTphuretted hydrogen, and produced similar effects on metallic solutions as those above stated. The yellow sublimate was a slight film of sulphur, and weighed about $\frac{4}{10}$ ths of a grain. This estimate of the sulphur must be considered merely as an approximation, as it was in a moist state. The precis quantity of water and sulphur thus obtained could not be determined with precision; but they could scarcely together have exceeded a grain in weight. The fixed substance at the bottom of the retort weighed 8.3 grains, and in its phy,

* This phrnomeron of the production of fire, accompanied by the separation of one of thio constituent parts of the hydrosulphuret, appears to be perfectly analogous to that observed by Sir H. Davy in the decomposi; tion of euchlorine gas at an elevated temperature. 
sical characters strictly resembled the supersulphuret of platina. From the experiments $I$ have made on it, which will hereafter be noticed, it appears to be a true sulphuret of platina containing 22 per cent. of sulphur.

Experiment 2.-Ten grains of the same hydrosulphuret, heated as in the above experiment, furnished similar results; the quantity of gas was precisely the same. The sulphuret obtained weighed 8.25 grains.

Experiment 3.-Twelve grains of hydrosulphuret, which in drying had been exposed to a higher temperature than that used in the preceding experiments, afforded similar products; but the sulphuretted hydrogen gas was less in quantity, it did not amount to a half of a cubical inch. This deficiency must be referred to the increased temperature, by which the gas was expelled and found in the water, as has been before noticed. The proportion of sulphureous acid gas was small, but the odour of it was more perceptible; there was also less water and more sulphur than in the experiments detailed: The quantity of sulphuret of platina bbtained amounted to 9.85 grains, which, on being decompounded at a red heat in a platina crucible, afforded results varying but little from those previously procured.

From these experiments we shall probably gain near approximations to the true composition of the hydrosulphuret of platina. They all closely agree as to the quantity of sulphur and platina, but differ as to the proportion of gas obtained; which has been accounted for. Of the three experiments above detailed, the first two appear to me to be most worthy of confidence. As the hydrosulphuret had in the first experiment been least exposed to the agency of the atmosphere, and consequently would furnish more correct results, I shall venture to make its data the basis for determining the proportions of its constituent parts. From this experiment the following results are derived:

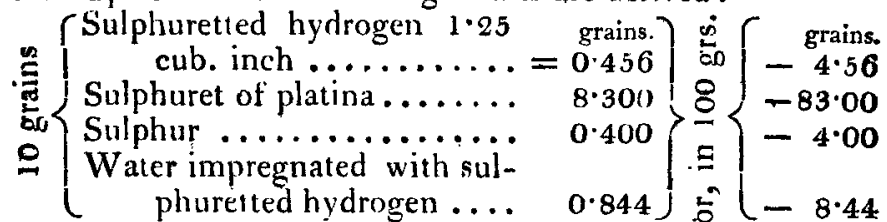

I have estimated the weight of 100 cubical inches of sulphuretted bydrogen gas at $36^{\circ} 5$ grains. It is derived from Sir H. Davy's statements, who says that 100 cubical inches weigh between 36 and 37 grains.

The sulphuret of platina contained 22 per cent. of sulphur; consequently the above 83 grains consisted of $64 \cdot 74$ 
platina +18.26 sulphur. I found that a cubical inch of distilled water, the barometer being at $30^{\circ}$, and thermometer at $60^{\circ}$, absorbed three cubical inches of sulphuretted hy. drogen; hence the eight grains would absorb about 0.34 of a grain; which added to the 4.56 grains $=4.9$ grains, Hence, 100 grains of hydrosulphuret of platina afforded

Platina ................64.74

Sulphur........ 18.26+4=22.26

Sulphuretted hydrogen gas about 5.00

Water .................. 8.00

$100 \cdot 00$

The most probable idea of its constitution is perhaps that it is compounded of the supersulphuret of platina and sulphuretted hydrogen*, and the results appear to agree very nearly with this supposition. According to my experiments in the Philosaphical Magazine for July, the supersulphuret of platina contains 28 per cent. of sulphur. Now 100 grains of the hydrosulphuret appear to contain 64.74 grains of metallic platina, which would require $23 \cdot 24$ grains of sulphur to be converted into the super-sulphuret. The 2ctual quantity obtained, amounts to about $22 \cdot 26$ grains. These coincidences were rather unexpected, and are much greater than could have been anticipated in experiments of this kind.

In the course of my experiments on the hydrosulphuret of platina, I had occasion several times to abserve a brown precipitate produced in a solution of platina by sulphuretted hydrogen in particular circumstances, especially when it was made over mercury, by letting up a solution of platina into a jar of the gas. I made some unsuccessful attempls to examine this substance, thinking its constitution might be different from the hydrosulphuret $I$ have described. I found it rapidly changed colour in contact with air, and became black: probably its composition may be determined by comparative experiments on the quantity of gas necessary to produce it. Should the results I have obtained be confirmed by future experiments, we shall probably become acquainted with a new class of com. pounds of which nothing is at present known, consisting

* Since my paper went to press, I made the following experiment, which, if it does not confirm the above idea, gives it a still higher degree of probability. A cubical inch of an aqueous solution of platina, exposed for about two days in a receiver of sulphuretted hydrogen gas over mercury, absorbed more than ten cubical inches of the gas. I found that a cubical inch of the same solution of platina required about eight cubical inches of hydrogen to reduce the platina to the metallic state. 
of the metallic sulphurets in union with sulphuretted hydrogen. This novel field of inquiry has hitherto been neglected; but it cannot be unwortby the attention of chemists. and it promises to lead to the explanation of many difficult ar abscure problems in chemistry.

Since the publication of my paper "On the Combinations of Sulphur and Phosphorus with Platina," I have observed a slight inadvertency I had committed, in the use of the words super and sub. In conformity with the language of chemistry, those compounds should have been called sulphuret and super-sulphuret; and phosphoret and superphosphoret. In prefixing the words super and sub to the common names, sulphuret, phosphoret, \& $x$. in any instance, it seems evidently to be implied that there are three distinct combinations of the kind; and in a relative sense, one is said to contain a deficiency, the other an excess, and the third, an intermediate proportion of the inflammable principle. What however, was at first used by accident and erroneously, must now be adopted from design, in the case of the compounds of platina with sulphur, if the experiments detailed in the preceding pages are correct.

I have already stated that the substance obtained by heating the hydrosulphuret of platina to redness in close vessels, is analogous in its physical and chennical properties to the super-sulphuret of platina. Thus its particles are loosely coherent, it is tasteless, it gives lustre to the fingers or paper like black-lead. It is unaffected by air and water, is insoluble in the mineral acids, and is decomponnded by the agency of heat and air, with similar phanomena to the super-sulphuret. It differs however in some respects from this substance. Thus its colour is blueish black, and the proportion of sulphur it contains, does not exceed 28 per cent.

In two experiments in which five grains of this substance were decomposed at a red heat in a platina crucible, $3 \cdot 9$ grains of platina were obtained.

And $5: 3 \cdot 9:: 100: 78$.

In a third experiment, nine grains of it afforded rather more than seven grains of platina. Hence it may be presumed that 100 grains of this substance contain

$\begin{array}{ll}\text { Platina } & \mathbf{7 8} \\ \text { Sulphur } & 22\end{array}$

100

From a comparison of my former experiments with these, 
these, it seems that there are three distinct combinations of platina with sulphur. The sub-sulphuret appears to contain one proportion of sulphur, the super-sulphuret two proportions, and the sulphuret one proportion and a half. The results which would be furnished from calculations of this kind, do not differ materially from those actually abtained.

The quantity of sulphur which combines with 100 grains of platina in these several compounds $I$ have here annexed.

Grs. of Platina. Sulphur.

$$
100\left\{\begin{array}{l}
19 \cdot 04 \\
28 \cdot 21 \\
38 \cdot 80
\end{array}\right\} \begin{aligned}
& \text { Sub-sulphuret * } \\
& \text { Sulphuret } \\
& \text { Super-sulphuret. }
\end{aligned}
$$

[To be continued.]

XL. Description of a Machine for pumping Water used in the East. By M. Chastellan, Author of "Travels in the Morea.+ "'

$\mathbf{T}$

HE art of irrigation ought to be better understood in countries which are subject to drought, than in those where abundant and periodical rains seem to render irrigation less necessary: there are circumstances nevertheless under which it is desirable, even in European countries, to procure an abundant and judicious distribution of water: and the expense of a machine with the necessary reservoir for this purpose will be speedily recompensed.

Watering by hand-engines is frequently disadvantageous, and always tedious. If the gardener has a large piece of ground to manage, he must necessarily water it during the heat of the day, for he cannot have sufficient time before sunrise or after sunset. Besides, the water which he employs for this purpose being newly drawn from a well, or having been contained in deep reservoirs, it cannot get rid of its too great coolness, or of that crudity, which are so injurious to plants; whereas the same water contained in large reservoirs and in uncovered canals for irrigation, soon acquires the temperature of the atmosphere, and the properties of rain water. The way in which the

* I am aware that the nomenclature here adopted is defective, and founded on an erroneous principle; that there is an excess, a deficiency, a neutral point in these combinations. It gives no information concerning the proportions of the constituents of the compounds. Professor Berzelius, I believe, intends shortly to publish some Observations on the Chemical Nomenclature, in which these deficiencies, I have no doubt, will be happily supplied.

t Bil. Phys, Econ. Dec. 1811. 